\title{
Dimensional Structural Mass Optimization of a Welded I-Profile Bridge Crane Girder
}

\author{
Nedim Pervan, Adis J. Muminovic, Elmedin Mesic, Mirsad Colic, Vahidin Hadziabdic
}

\begin{abstract}
This paper presents the methodology for the development of an optimization model for the optimization of the cross-section dimensions of a bridge crane girder designed as a welded I-profile. To carry out this optimization, the CAD/CAE software package CATIA V5 was used. In order to develop an optimization model, a CAD geometrical model and structural analysis model were developed. Optimization was carried out by the iterative method using a simulated hardening algorithm. Additionally, the optimization process is carried out by using the PEO (Product Engineering Optimization) CATIA module that contains tools for setting the optimization criteria, design parameters, constraints, and algorithms. The goal of the optimization is to achieve the minimal mass of the girder, while satisfying all functional and geometrical constraints. As a result of the optimization process, minimal girder dimensions were obtained and due to that, a minimal amount of material can be used for the manufacturing of the girder.
\end{abstract}

Keywords: crane girder; optimization; parameters; simulated hardening

\section{INTRODUCTION}

Today, engineers, designers and researchers always try to optimize theirs designs so that a minimum amount of material can be used, or that minimum stresses can be achieved. The allowed stresses are pushed to their minimum limits. If someone wants to optimize his or her part, from the aspect of the minimum mass or minimum stresses, they need to know the precise stress distribution inside the loaded part. Computer aided optimization $(C A O)$ is connected to and based on the numerical analysis processes.

The goal of this paper and this research is to present the methodology for the development of an optimization model for the optimization of the cross-section dimensions of a bridge crane girder designed as a welded I-profile. A detail description of the possibilities and characteristics of a PEO (Product Engineering Optimization) module for the structural optimization in a CAD/CAE (Computer Aided Design/Computer Aided Engineering) software CATIA (Computer Aided Three-dimensional Interactive Application) is presented. Firstly, it is necessary to develop a CAD (Computer Aided Design) parametric model and numerical model of a bridge crane girder. Characteristic design dimensions of an I-profile are chosen as optimization parameters.

Dimensioning is the process of choosing the right dimensions of a machine part in correlation to the function of that part, its mechanical properties, stiffness, standards, price, etc. That correlation is not always exactly (mathematically) known. Because of that, the mathematical function (the goal function of optimization) is not always easy to set. In this case, the only way to carry out optimization is to use the iterative process. When using the iterative process, it is possible to come close to an optimal design by taking into consideration all of the above-mentioned constraints. It is only possible to carry out this type of iterative process by using computer software. Sometimes, in terms of classical optimization problems, the iterative process is carried out only for the most important constraints, other constraints are chosen as constant values. Speed is not the only benefit of using computer software for the optimization. Optimization via computer software can optimize parts for multiple constraints simultaneously. Additionally, by using computer software, it is possible to carry out optimization for the assembly, not only for one part. The results of optimization for one part can be used as input data for another part in the assembly. [1-2].

The subject of the research in this paper is the optimization of the cross-section dimensions of a bridge crane girder designed as a welded I-profile. Bridge cranes have two main girders with the rails for wheels movement. The ends of the main girders are fixed to transverse supports, which have wheels for the movement of the entire bridge crane (Fig. 1).

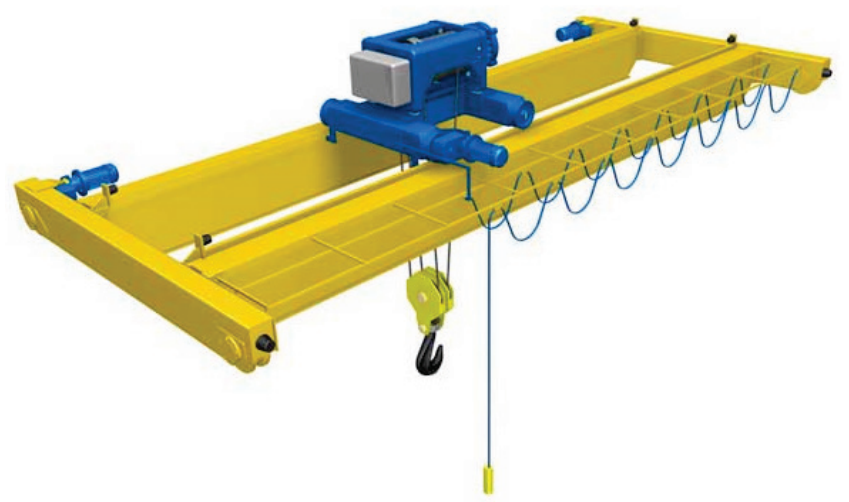

Figure 1 Bridge crane with two main girders

There are a lot of research papers about the structural optimization used in the design process. Usually, it is the topology optimization, or the optimization of the shape and size [3-12].

\section{STRUCTURAL OPTIMIZATION}

Optimization is the process of obtaining the best solution for the given constraints. The main goal of engineers and designers during the design process is to minimize the usage of the used materials or to maximize the benefits. The abovementioned statement must be formulated as a mathematical 
function of some unknown variables. Optimization can be defined as a mathematical problem of the minimization or maximization of the function.

There are many different methods for optimization. The most common method for engineers is the method of simulated hardening. This method is based on the process of metal cooling during hardening. It was developed by Kirkpatrick, Gellat and Vecchi [13].

Simulated hardening is the stochastic method for searching for a good approximation of the global minimum of the function. The simulated hardening method is based on the process of the heating and controlled cooling of metal materials with the goal of exerting influence on the metal structure and inside errors. This algorithm can find the global minimum in a certain amount of time [14].

The algorithm begins with the initial design vector $X_{1}$ (iteration number $i=1$ ) and a high value of the temperature $T$. By random generation of a new point $X_{i+1}$, the nearby first point, the value of the goal function can be calculated by using the following equation:

$$
\Delta E=E_{i+1}-E_{i}=\Delta f=f_{i+1}-f_{i}=f\left(X_{i+1}\right)-f\left(X_{i}\right)
$$

If $f_{i+1}$ is smaller than $f_{i}$ (negative value of $\Delta f$ ), point $X_{i+1}$ is accepted as a new design vector. If $\Delta f$ has a positive value, point $X_{i+1}$ is accepted as a new design vector with the probability of $\mathrm{e}^{-\Delta E / k T}$. That means that if the value of a randomly generated number is bigger than $\mathrm{e}^{-\Delta E / k T}$, point $X_{i+1}$ is not accepted as a design vector. With this process, one iteration of the optimization process is finished.

If the point $X_{i+1}$ is not accepted, the generation process of the new point is based on the Metropolis criteria:

$$
P\left(E_{i+1}\right)=\exp \left(\frac{\Delta E}{k T}\right)
$$

For the simulation of the thermal balance achievement on every temperature, a number of new points is selected $(n)$ $X_{i+1}$. These points must be analyzed for the defined values of temperature.

When a number of new design points $X_{i+1}$, analyzed for the defined value of temperature, become bigger than the number $n$, the temperature $T$ is reduced by an already defined factor $c(0<c<1)$ and the whole process repeats. It is considered that the process converges when the value of temperature is small enough or when the change of the value of the goal function $\Delta f$ is small enough.

For good optimization, the most important thing is to formulate the optimization problem correctly. An optimal solution will have satisfactory results only if the optimization problem is formulated in the right way.

For the design optimization, a five-step procedure for the optimization problem formulation is usually used. The first step is to define the optimization goal. In this case, the optimization goal is to find the optimal dimensions of the girder cross section to achieve the minimum mass of the girder for the constant length and loading capacity. Stresses in the girder must be lower than the allowed stresses for the material of the girder. The maximum displacement should not be bigger than $L / 1000$. Additionally, it is necessary to check the possibility for lateral torsional buckling $[15,16]$.

The second step is to collect the data about the optimization problem. A static schematic diagram is shown in Fig. 2a. The length of the girders is $16 \mathrm{~m}$ and the maximal load of the bridge crane is $20 \mathrm{~T}$.

For the numerical finite element analysis and for the optimization analysis of the girders, the $C A D / C A E$ system CATIA is used. The material of the bridge crane is stainless steel S235.

In the third step, it is necessary to define the parameters that describe the system. The mass of the girder is in the function of the volume (dimensions) of the girder and material density. The dimensions of the girder cross section are shown in Fig. 2b, and these dimensions are taken as design parameters.

The length of the girder $L$ and the material (density of the material $\rho$ ) are constant during the optimization process. Due to that, they are removed from the optimization problem formulation. The same applies to the rails. Rails have standard dimensions $(a=50 \mathrm{~mm}$ and $c=40 \mathrm{~mm})$. The rest of the girder cross section dimensions $\left(b, t_{1}, h\right.$ and $\left.t\right)$ are free parameters and they are taken as the design parameters for optimization.

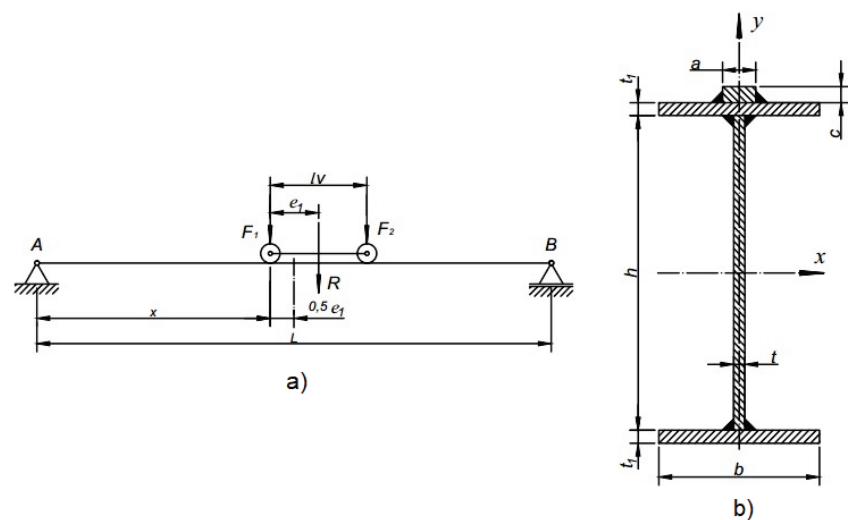

Figure 2 a) Schematic diagram of the bridge crane; b) Girder cross section

The fourth step is to define the goal function. The goal of the optimization is to find the dimensions of the girder cross section, which will give the minimum mass of the girder for the applied constraints. The mass of the girder can be expressed as the function of the design parameters.

$f\left(b, t_{1}, h, t\right)=m=A \cdot L \cdot \rho \cdot g$

In the last step of the optimization, it is necessary to define the constraints. Constraints are applied in the form of the allowed values for the maximum stress, deflection and lateral torsional buckling.

Moreover, constraints must be applied in the form of the values for the minimum dimensions which the cross-section needs to have. 


\section{DEVELOPMENT OF CAD AND NUMERICAL MODELS}

During the development of the 3D CAD model, the goal is not just to get the visualization of the design, but also to get a functional 3D CAD model. A functional 3D CAD model can be developed by using parametric modelling.

The term parametric design is associated with the parametric systems and it is defined as "a process of designing with parametric models in a virtual surrounding where the geometrical and parameter variation are natural" [17-19].

The parametric model of a bridge crane girder is developed by using the CATIA software package. First, the 3D model of the bridge crane girder is developed by using the geometrical and dimensional constraints. After the 3D model is developed, parametrization of design parameters, defined in Chapter 2 of this paper, can be carried out. An example of the relation between the parameters is shown in Fig. 3.

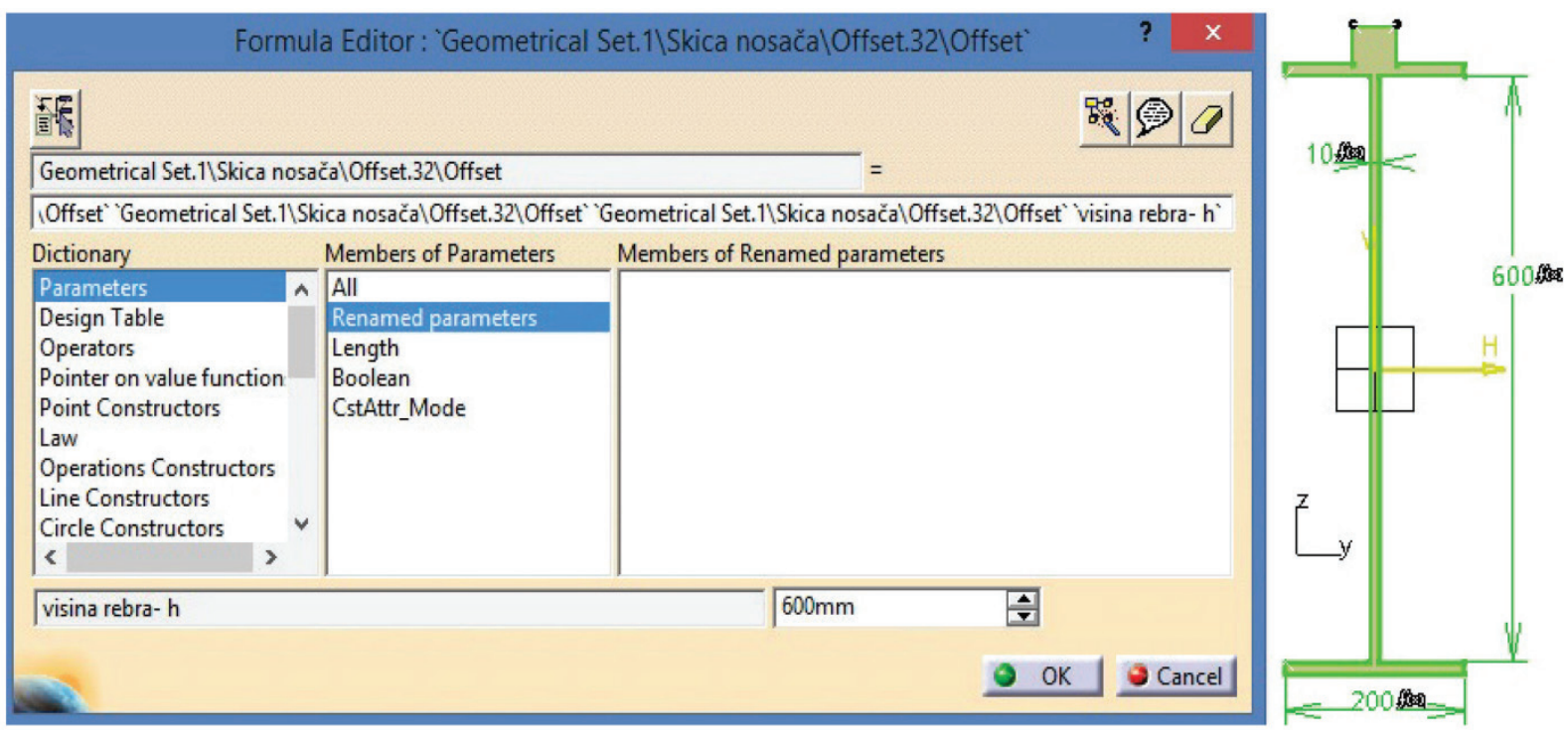

Figure 3 Relation between parameters

The finite element structural analysis via the Generative Structural Analysis in the software package CATIA module is carried out by using the above-mentioned developed $3 D$ $C A D$ parametric model. The first step in the process of the finite element structural analysis is to carry out the discretization of the girder by using finite elements [20-26].

The second step is to apply the constraints. In this case, the girder is supported at both ends. One end has all translations fixed and all rotation allowed, the second end is a movable support with all translations and rotations allowed (Fig. 2a).

The third step in the process of the finite element structural analysis is to apply the loads on the girder. All loads from real working conditions must be applied to the girder. The girder is loaded with their own weight, the weight of the load which it is carrying and the weight of the winch.

The results of the finite element structural analysis, carried out on the initial 3D CAD model, are the values of the displacements and Von Mises stresses. These values will be used as the constraints for optimizations (Fig. 4).

As it has earlier been mentioned, one of the constraints should be the value for lateral torsional buckling. To get this value, it is necessary to carry out a new structural analysis for this case. The static analysis of lateral torsional buckling is taken as a referent analysis.

The analysis of lateral torsional buckling in the CATIA software package gives 10 modes of the torsional twist. Only the first three or four modes are important in practical applications [27]. For the bridge crane girder, only the first mode is taken into account as a relevant one. This will reduce the time of calculations (Fig. 5).

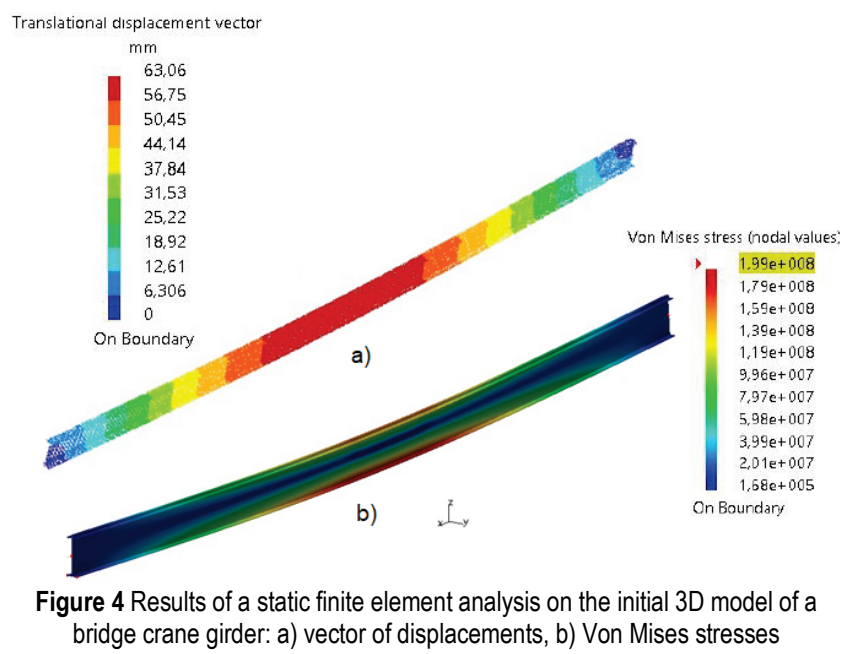

Fig. 5a shows the deformation of the girder without lateral bracing during lateral torsion buckling loads. The coefficient of deflection for this case is 0.324 . Fig. $5 \mathrm{~b}$ shows the deformation of the girder with three lateral bracings. For this case, the coefficient of deflection is 4.45 . It can be 
noticed that deformation is significantly bigger in the case where lateral bracings are not applied, i.e. girder will deform because the coefficient of deflection is lower than 1 .
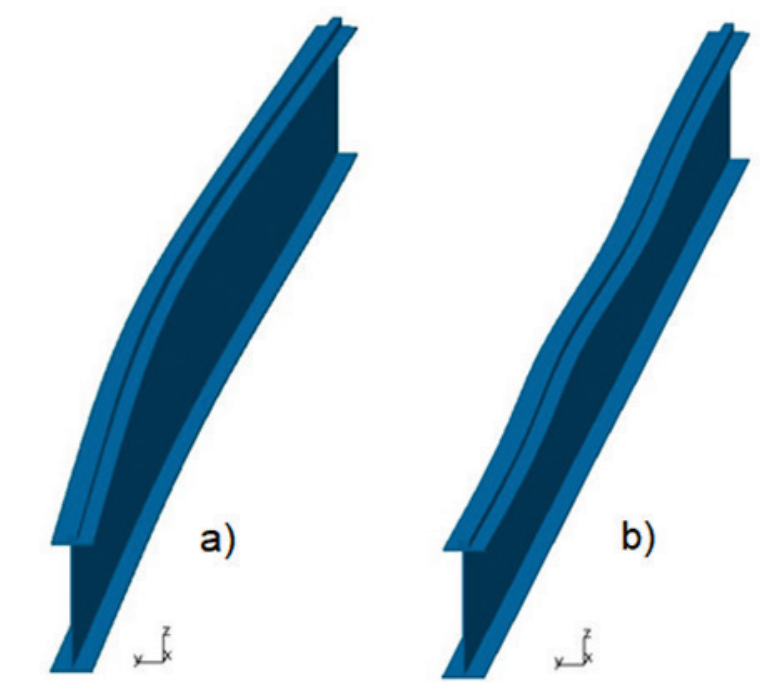

Figure 5 Deformation of the girder; a) without lateral bracing, b) with three lateral bracings

\section{DEVELOPMENT OF AN OPTIMIZATION MODEL \\ 4.1 The Mathematical Model}

For the development of an optimization model, the nonlinear SUMT (Sequential Unconstrained Minimization Technique) method was used. According to this method, the so-called penalty functions are introduced. In these processes, approximation is carried out by adding the penalty member to the goal function in the area where constraints are not satisfied [28]. For the goal function, a girders mass is selected, which has the following form:

$$
f\left(b, t_{1}, h, t\right)=\left(2 b \cdot t_{1}+h \cdot t+a \cdot c\right) \cdot L \cdot \rho \cdot g
$$

where: $b, t_{1}, h, t, a$ and $c$-are shown in Fig. $2, \rho$ - the specific mass of steel, $g$ - speed of gravity.

The constraints that the design should meet:

- flanges:

$$
\begin{aligned}
& \sigma_{v}-v \cdot \sigma_{u, p 1} \geq 0 \\
& \sigma_{v}-v \cdot \sigma_{u, p 2} \geq 0 \\
& t_{1}-1.2 t \geq 0 \\
& 2 t-t_{1} \geq 0
\end{aligned}
$$

- the web:

$$
\begin{aligned}
& \sigma_{v}-v \cdot \sigma_{u, r} \geq 0 \\
& \sigma_{u x}-v \cdot \sigma_{s, r} \geq 0 \\
& \sigma_{v}-\sigma_{u x} \geq 0 \\
& t-5 \geq 0
\end{aligned}
$$

- deflection:

$w_{d}-w \geq 0$

where: $\sigma_{v}$ - the tension on the extension limit, $\sigma_{u, p 1}$ - maximal tension in the upper flange, $\sigma_{u, p 2}-$ maximal tension in the lower flange, $\sigma_{u, r}$ - maximal tension in the girders web, $\sigma_{s, r}$ flexion tension in the girders web, $\sigma_{u x}$ - border tension on buckling, $v$ - the level of security.

For resolving the cost function minimization problem, the Eq. (4) with constraints, Eq. (5), Eq. (6) and Eq. (7), which have a form of inequality $c_{j}=\left(b, t_{1}, h, t\right) \geq 0, j=1,2$, $\ldots, m$, and a penalty function method SUMT are used. With the introduction of the penalty function here, a new cost function is formed, Eq. (8) without limitations, and then the function minimum is determined:

$$
\Phi\left(b, t_{1}, h, t, r\right)=f\left(b, t_{1}, h, t\right)+r \sum_{j=1}^{m} \frac{1}{c_{j}=\left(b, t_{1}, h, t\right)}
$$

To solve the problem, a previously made computer program in FORTRAN was adjusted [29].

\subsection{The Numerical Model}

The same problem was solved numerically, and for that purpose, the CATIA module Product Engineering Optimizer was used. The module has iterative methods that can be used for any parameter [30]. In this case, the so-called simulated hardening algorithm is used. This algorithm was chosen because the goal function is unknown, and because this algorithm can avoid local minimums and find the global maximum. For this algorithm, the speed of convergence can be chosen [31-33].

After the definition of the goal function, design parameters and constraints. The results of the optimization can be presented in the form of diagrams for different combinations of design parameters. (Fig. 6 and Fig. 7). Fig. 6a shows the changes of the goal function in the form of the value of mass for all iterations. In the same figure, a diagram of the best solution (the best value of the goal function) is also shown. Fig. $6 \mathrm{~b}$ shows the changes of the height of the web and the deviation of the values of the deflection from the allowed values during the iteration process. It can be noticed that when increasing the values for the height of the web, deviation is going close to zero, which means that the deflection has lover values. From Fig. 7a, it can be noticed that the maximal deflection is $15.96 \mathrm{~mm}$, which means that the constraints for deflection are fulfilled.

Furthermore, from Fig. 7b, it can be noticed that maximal stresses occur at the lover part of the girder and that the maximal value is $82.4 \mathrm{MPa}$, which is lower than the constraint of $160 \mathrm{MPa}$. 

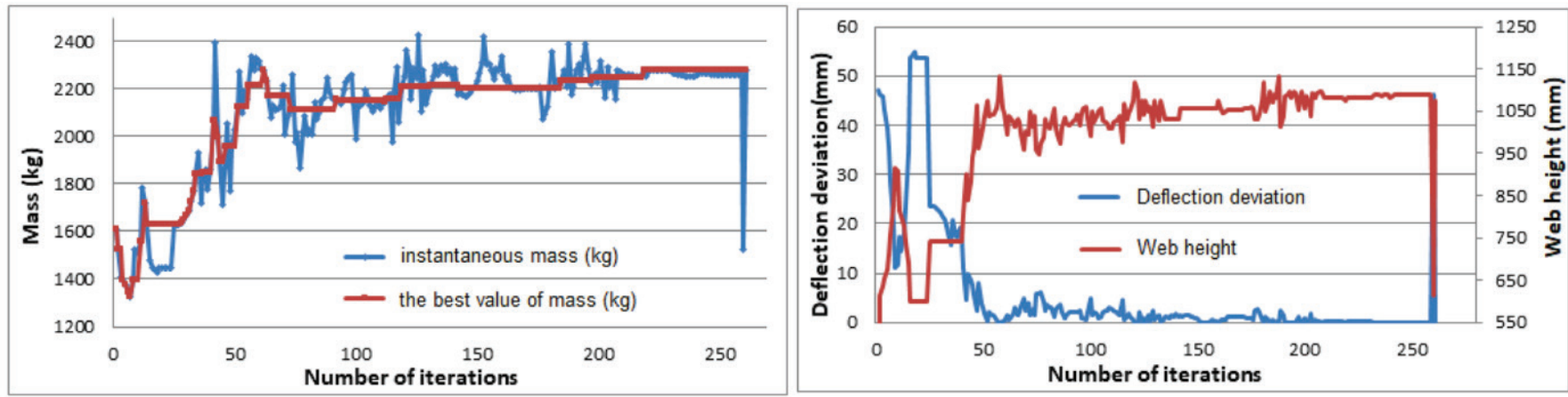

Figure 6 Parameter changes during the iteration process a) relation between the current and best mass of the girder $\mathrm{b}$ ) relation between deflection and the height of the web

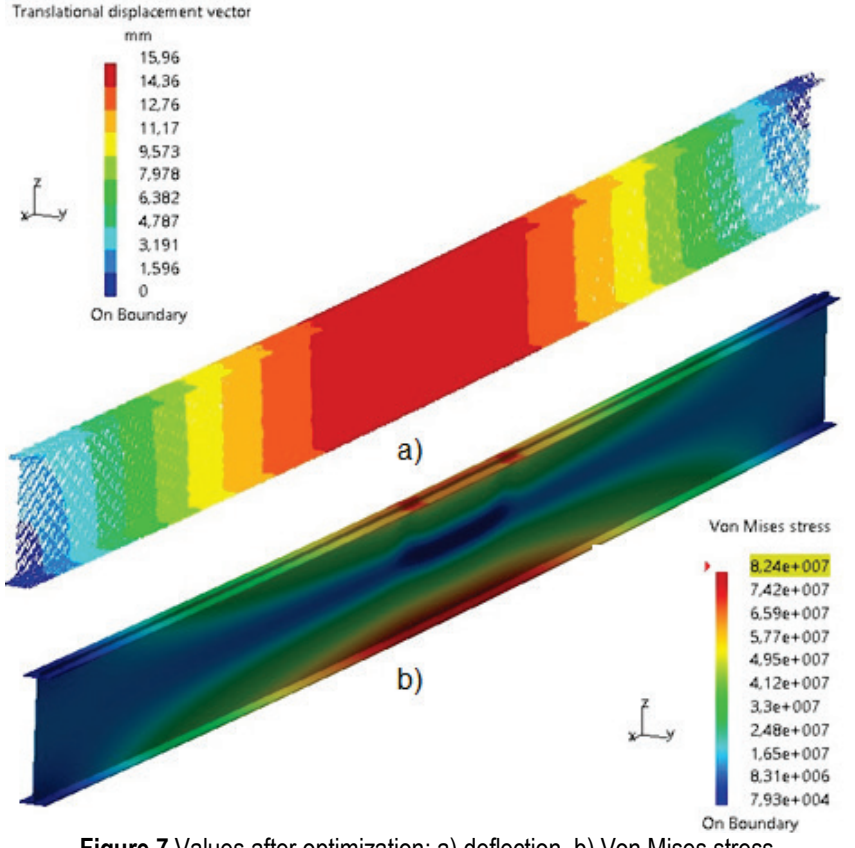

Figure 7 Values after optimization; a) deflection, b) Von Mises stress

\section{RESULTS}

Fig. 8a shows diagrams of the dependency of the mass of the girder to the number of lateral bracing for different lengths of the girder. It can be noticed that the number of lateral bracing does not have a significant effect on the mass of the girder. This is an important fact, because for the lengths of $16 \mathrm{~m}, 20 \mathrm{~m}$, and $25 \mathrm{~m}$ of the girder, the optimization algorithm could not find the solution without using lateral bracing. The constraint for lateral torsional buckling could not be fulfilled. After adding only one lateral bracing at the middle of the girder, optimization was carried out successfully.

Fig. $8 \mathrm{~b}$ shows the correlation between the mass of the girder and the allowed deflection for the length of $16 \mathrm{~m}$, the free length of torsional buckling of $4 \mathrm{~m}$ and the ratio of $h / t=$ 120. The calculation is carried out for the loads of $100 \mathrm{kN}$ and $200 \mathrm{kN}$ and the ratios of $L / f=1000,950,900,850,800$, 850 . By increasing the value of the allowed deflection, the needed stiffness of the girder is reduced, which means that the girder can have smaller dimensions and a lower mass.
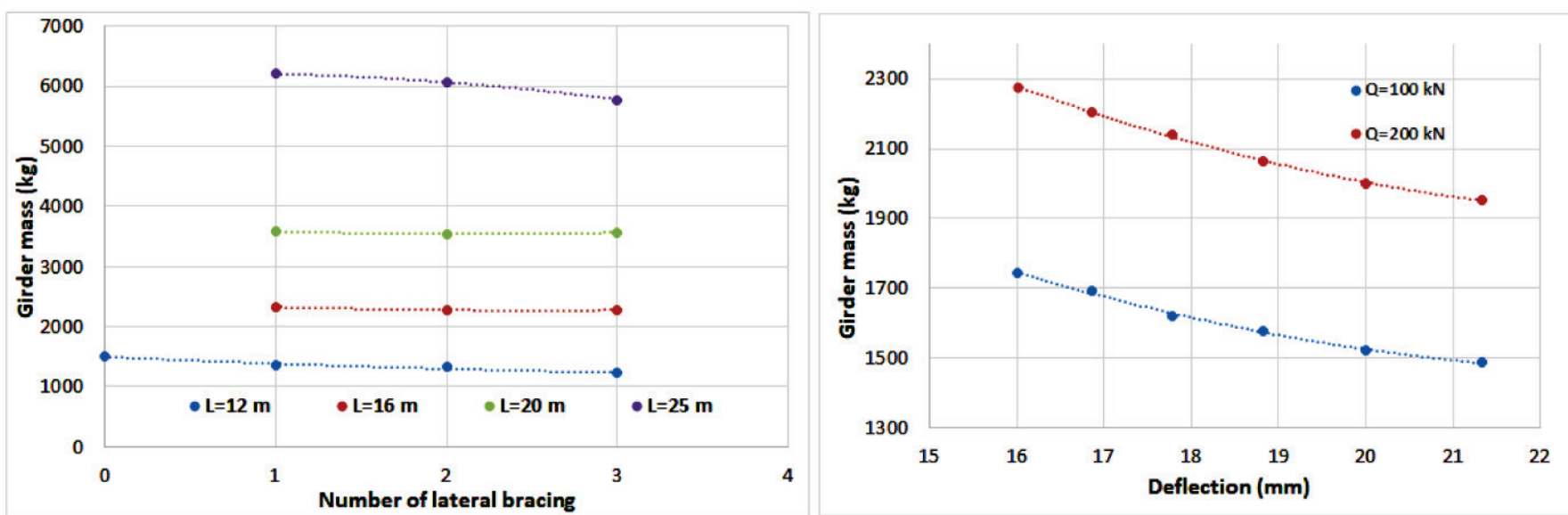

Figure 8 Mass of the girder; a) for different lengths of the girder and a different number of laterals bracing for the load of $200 \mathrm{kN}, \mathrm{b}$ ) in correlation to the allowed deflection for a length of $16 \mathrm{~m}$, the free length of torsional buckling of $4 \mathrm{~m}$ and the ratio of $h / t=120$

Fig. 9a shows the optimal values of the mass of the girder for the lengths of $12 \mathrm{~m}$ and $16 \mathrm{~m}$ and the loads of 50,100 , $160,200,250$ and $320 \mathrm{kN}$. These values of mass result from the structural optimization of the software CATIA. It is important to notice that the results obtained by the structural optimization in the CATIA module Product Engineering
Optimizer are the same as the results obtained by the SUMT (Sequential Unconstrained Minimization Technique) method.

The $h / t$ ratio also has an important effect on the mass of the girder. For the same length of the girder, the same free length of the torsional buckling and the same loads, a 
different mass can be obtained by changing the height and thickness of the web. An increase of the $h / t$ ratio has a positive impact on the deflection of the girder, and the constraint for the allowed deflection was fulfilled faster.

Fig. $9 \mathrm{~b}$ shows the correlation between the mass of the girder and the $\mathrm{h} / \mathrm{t}$ ratio for the load of $200 \mathrm{kN}$, the allowed deflection $L / 1000$ and the free length of the buckling of $4 \mathrm{~m}$.
Girders with a high value of the $\mathrm{h} / \mathrm{t}$ ratio have a problem because buckling can occur. It is necessary to check the girder for buckling and if necessary, to add an additional vertical and/or horizontal bracing on the web.
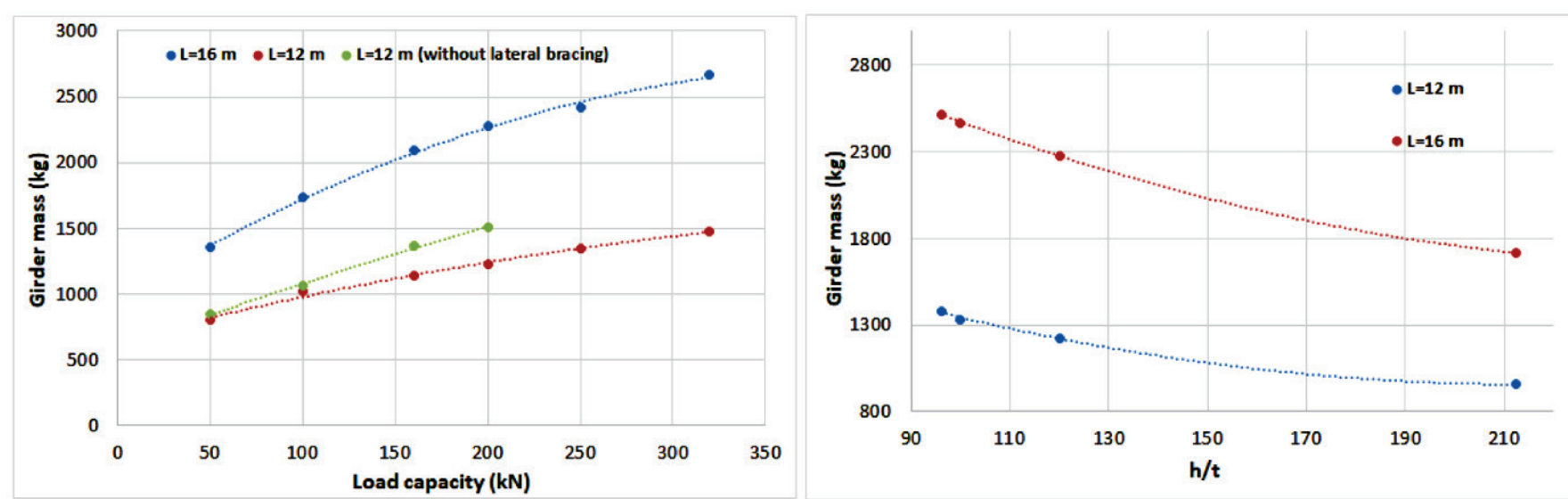

Figure 9 Mass of the girder; a) in correlation to the load of the crane for ratio $h / t=120$ and free length of buckling of $4 \mathrm{~m}, \mathrm{~b}$ ) in correlation to the ratio $h / t$ for load of $200 \mathrm{kN}$, allowed deflection $L / 1000$ and free length of buckling of $4 \mathrm{~m}$

\section{CONCLUSION}

The goal of the optimization process carried out in this paper was to find the minimal value of the mass of the bridge crane girder designed as a welded I-profile. The mass of the girder depends on the input parameters such as the length of the girder, the load of the bridge crane, the allowed deflection and the ratio between the height and the thickness of the girder web. Optimization is carried out for different combinations of the above-mentioned input parameters.

For a numerical analysis and optimization, the $C A D / C A E$ system $C A T I A$ V5 was used. A structural numerical analysis is the first step that needed to be carried out to start with the optimization process. Using the structural numerical analysis data for displacements, the stresses and buckling coefficients can be obtained at all points of the design. With the help of computers and software, the calculation process is fast. Additionally, it is easy to control the values of all parameters and to obtain certain conclusions about the behaviour of the design for the applied constraints.

It is important to notice that for a successful optimization of the design, it is not enough to know how to work with computer software, but it is also very important to understand the real constraints of the design during exploitation. This knowledge is important if someone wants to develop an optimization model which is very similar to the real design. It is important to know how design is supported, where the loads are, how to implement some of the standards and recommendations based on experience. Every optimization model and optimization process have some errors, but it is important to minimize those errors and to develop such a model that is very close to the real one.

The Product Engineering Optimizer module in combination with the finite element method is a powerful tool which is easy to use and which gives a lot of useful data about the behavior of the design for different input parameters (dimensions, loads etc.). When using this module, it is possible to design lighter and more economical designs. Additionally, an important advance of this module lies in its fast calculation properties, which reduce the time of the design or redesign processes. The task which needs to be carried out by engineers is to develop an optimization model, run the calculation, and analyse the results. Engineers need to have some real life experience to precisely develop the optimization model and to analyse the results in the right manner.

A disadvantage of this module is the need to have computers with height characteristics, the so-called workstations. With workstations, it is possible to develop advance optimization models and to carry out calculations with a small amount of errors.

The optimization methodology developed in this research can be used for the optimization of similar designs. The mass of the girder can be additionally minimized by analysing others shapes of the girder cross section. For the results presented in this paper, it can be noticed that the material at the end of the girder is not used properly. It is possible to remove some of the material at those places of the girder. A girder can have a different height at the ends and at the middle.

\section{REFERENCES}

[1] Ognjanović, M. (1990). Design Methodology. Faculty of Mechanical Engineering Belgrade, Belgrade.

[2] Singiresu, S. R. (2009). Engineering Optimization: Theory and Practice. Fourth edition, John Wiley \& Sons, Inc., New Jersey.

[3] Muminovic, A. J., Muminovic, A., Mesic, E., Saric, I., \& Pervan, N. (2019). Spur Gear Tooth Topology Optimization: 
Finding Optimal Shell Thickness for Spur Gear Tooth produced using Additive Manufacturing. TEM Journal, 8(3), 788-794. https://doi.org/10.18421/TEM83-13

[4] Swantner, A. \& Campbell, M. I. (2012). Topological and parametric optimization of gear trains. Engineering Optimization, 44(11), 1351-1368. https://doi.org/10.1080/0305215X.2011.646264

[5] Gardan, N. \& Schneider, A. (2015). Topological optimization of internal patterns and support in additive manufacturing. Journal of Manufacturing Systems, 37(1), 417-425. https://doi.org/10.1016/j.jmsy.2014.07.003

[6] Mirzendehdel, A. M. \& Suresh, K. (2016). Support structure constrained topology optimization for additive manufacturing. Computer-Aided Design, 81, 1-13, https://doi.org/10.1016/j.cad.2016.08.006

[7] Mezzadri, F., Bouriakov, V., \& Qian, X. (2018). Topology optimization of self-supporting support structures for additive manufacturing. Additive Manufacturing, 21, 666-682. https://doi.org/10.1016/j.addma.2018.04.016

[8] Wu, J., Clausen, A., \& Sigmund, O. (2017). Minimum compliance topology optimization of shell-infill composites for additive manufacturing. Computer Methods in Applied Mechanics and Engineering, 326, 358-375. https://doi.org/10.1016/j.cma.2017.08.018

[9] Muminovic, A. J., Mesic, E., Muminovic, A., Colic, M., \& Braut, S. (2016). Optimisation of Central Disc Position on Elastic Rotor Suported with Active Magnetic Bearings. Journal of Multidisciplinary Engineering Science and Technology (JMEST), 3(9).

[10] Fancello, E. A. (2006). Topology optimization for minimum mass design considering local failure constraints and contact boundary conditions, Structural and Multidisciplinary Optimization, 32(3), 229-240. https://doi.org/10.1007/s00158-006-0019-9

[11] Fancello, E., Haslinger, J., \& Feijóo, R. (1995) Numerical comparison between two cost functions in contact shape optimization. Structural Optimization, 9(1), 57-68. https://doi.org/10.1007/BF01742646

[12] Hilding, D., Klarbing, A., \& Petersson, J. (1999). Optimization of structures in unilateral contact. Applied Mechanics Reviews, 52(4), 139-160. https://doi.org/10.1115/1.3098931

[13] Singiresu, S. R. (2009). Engineering Optimization: Theory and Practice. $4^{\text {th }}$ edition, John Wiley \& Sons, Inc., New Jersey.

[14] Jasbir, S. A. (2012). Introduction to optimum design. $3^{\text {rd }}$ edition, Elsevier, Oxford.

[15] Delić, M., Čolić, M., Mešić, E., \& Pervan, N. (2017). Analytical Calculation and FEM Analysis Main Girder Double Girder Bridge Crane. TEM Journal, 6, 48-52, https://doi.org/10.18421/TEM61-07

[16] Delić, M., Pervan, N., Čolić, M., \& Mešić, E. (2019). Theoretical and experimental analysis of the main girder double girder bridge cranes. International Journal of Advanced and Applied Sciences, 6(4), 75-80. https://doi.org/10.21833/ijaas.2019.04.009

[17] Saric I., Pervan N., Muminovic A., \& Colic, M. (2018). Development of Integrated Intelligent Cad System for Design of Shafts. Tehnički vjesnik, 25(Supplement 1), 99-104. https://doi.org/10.17559/TV-20170521194820

[18] Saric, I., \& Muminovic, A. J. (2018): Development of integrated intelligent CAD system for synthesis and stressdeformation analysis of pressure vessels. International Journal of Engineering \& Technology, 7(1). https://doi.org/10.14419/ijet.v7i1.8666

[19] Pervan, N., Muminovic, A. J, Muminovic, A., \& Delic, M. (2019). Development of Parametric CAD Model and Structural
Analysis of the Car Jack. Advances in Science and Technology Research Journal, 13(3), 24-30, https://doi.org/10.12913/22998624/109791

[20] Mešić, E., Avdić, V., Pervan, N., \& Repčić, N. (2015). Finite element analysis and experimental testing of stiffness of the Sarafix external fixator. Procedia Engineering, 100, 15981607. https://doi.org/10.1016/j.proeng.2015.01.533

[21] Mesic, E., Muminovic, A. J., \& Repcic, N. (2012). Geometrical Modelling and Structural Analysis of the Sarafix Fixator Configurations. Annals of DAAAM for 2012 \& Proceedings of the 23 $3^{\text {rd }}$ International DAAAM Symposium, 0069-0074.

[22] Muminovic, A. J., Saric, I., \& Repcic, N. (2011). Software for Deformity and Stress Condition of 2D Truss Beams Analysis. Annals of DAAAM for 2011 \& Proceedings of the $22^{\text {nd }}$ International DAAAM Symposium, 1225-1226.

[23] Mešić, E., Pervan, N., Repčić, N., \& Muminović, A. (2012). Research of influential constructional parameters on the stability of the fixator Sarafix. Proceedings of the $23^{\text {rd }}$ International DAAAM Symposium, 561-564.

[24] Mešić, E., Avdić, V., \& Pervan, N. (2015). Numerical and experimental stress analysis of an external fixation system. Folia Medica Facultatis Medicinae Universitatis Saraeviensis, 50(1), 74-80.

[25] Muminovic, A. J., Saric, I., \& Repcic, N. (2014). Analysis of Stress Concentration Factors Using Different Computer Software Solutions. Procedia Engineering, 69, 609-615. https://doi.org/10.1016/j.proeng.2014.03.033

[26] Muminovic, A. J., Saric, I., \& Repcic, N. (2015). Numerical Analysis of Stress Concentration Factors. Procedia Engineering, 100, 707-713. https://doi.org/10.1016/j.proeng.2015.01.423

[27] Muminovic, A. J., Braut, S., Muminovic, A., \& Saric, I. (2014). Numerical and Analytical Analysis of Elastic Rotor Natural Frequency. TEM Journal, 3(4), 323-328.

[28] Štajer A. (2014). Rešavanje problema minimizacije sa ograničenjima primenom kaznenih funkcija, University of Novi Sad, Faculty of Sciences, Novi Sad.

[29] Colic, M., \& Colic, M. (2014). Dimensioning and FEM analysis of the lever tongs holding the by the friction force. Proceedings of the $18^{\text {th }}$ International TMT Symposium, 405408.

[30] Pervan, N., Čolić, M., Šarić, I., \& Hadžiabdić, V. (2016). Analysis of the Haulage Ropes on Ropeways in Case of Accidental Loads. TEM Journal, 5(2), 171-174.

[31] Pervan, N., Mešić, E., Čolić, M., \& Avdić, V. (2015). Stiffness Analysis of the Sarafix External Fixator based on Stainless Steel and Composite Material. TEM Journal, 4(4), 366-372.

[32] Pervan, N., Mešić, E., \& Čolić, M. (2017). Stress analysis of external fixator based on stainless steel and composite material. International Journal of Mechanical Engineering \& Technology, 8(1), 189-199.

[33] Pervan, N., Mešić, E., Čolić, M., \& Avdić, V. (2016). Stiffness analysis of the sarafix external fixator of composite materials. International Journal of Engineering \& Technology, 5(1), 2026. https://doi.org/10.14419/ijet.v5i1.4912

\section{Authors' contacts:}

Nedim Pervan, PhD, Assistant Professor

University of Sarajevo, Faculty of Mechanical Engineering,

Vilsonovo setaliste no. 9 ,

71000 Sarajevo, Bosnia and Herzegovina

Tel.: +38733729 800

pervan@mef.unsa.ba 
Adis J. Muminovic, PhD, Assistant Professor

(Corresponding author)

University of Sarajevo, Faculty of Mechanical Engineering,

Vilsonovo setaliste no. 9 ,

71000 Sarajevo, Bosnia and Herzegovina

Tel.: +38733729 800

adis.muminovic@mef.unsa.ba

Elmedin Mesic, PhD, Associate Professor

University of Sarajevo, Faculty of Mechanical Engineering,

Vilsonovo setaliste no. 9 ,

71000 Sarajevo, Bosnia and Herzegovina

Tel.: +38733729800

mesic@mef.unsa.ba

Mirsad Colic, PhD, Full Professor

University of Sarajevo, Faculty of Mechanical Engineering,

Vilsonovo setaliste no. 9 ,

71000 Sarajevo, Bosnia and Herzegovina

Tel.: +38733729 800

colic@mef.unsa.ba

Vahidin Hadziabdic, PhD, Associate Professor

University of Sarajevo, Faculty of Mechanical Engineering,

Vilsonovo setaliste no. 9 ,

71000 Sarajevo, Bosnia and Herzegovina

Tel.: +387 33729800

hadziabdic@mef.unsa.ba 